\title{
Researching health in diverse neighbourhoods: critical reflection on the use of a community research model in Uppsala, Sweden
}

\author{
Sarah Hamed', Sonja Klingberg ${ }^{2}$, Amina Jama Mahmud ${ }^{3}$ and Hannah Bradby ${ }^{1^{*}}$ (1)
}

\begin{abstract}
Objective: A community research model developed in the United Kingdom was adopted in a multi-country study of health in diverse neighbourhoods in European cities, including Sweden. This paper describes the challenges and opportunities of using this model in Sweden.

Results: In Sweden, five community researchers were recruited and trained to facilitate access to diverse groups in the two study neighbourhoods, including ethnic, religious, and linguistic minorities. Community researchers recruited participants from the neighbourhoods, and assisted during semi-structured interviews. Their local networks, and knowledge were invaluable for contextualising the study and finding participants. Various factors made it difficult to fully apply the model in Sweden. The study took place when an unprecedented number of asylum-seekers were arriving in Sweden, and potential collaborators'time was taken up in meeting their needs. Employment on shortterm, temporary contracts is difficult since Swedish Universities are public authorities. Strong expectations of stable full-time employment, make flexible part-time work undesirable. The community research model was only partly successful in embedding the research project as a collaboration between community members and the University. While there was interest and some involvement from neighbourhood residents, the research remained University-led with a limited sense of community ownership.
\end{abstract}

Keywords: Sweden, Healthcare research, Community research

\section{Introduction}

This paper explores the use of a community research model adopted in Sweden as part of a multi-country healthcare project [1]. The model defines community research as "the practice of engaging community members as co-researchers to research issues within their own communities with a view of accessing community specific issues", to offer community members ownership of the research agenda, and facilitate access to specific issues or groups [2]. Different partners with different skills, understandings and experiences can address complex

\footnotetext{
*Correspondence: hannah.bradby@soc.uu.se

${ }^{1}$ Department of Sociology, Uppsala University, Uppsala, Sweden

Full list of author information is available at the end of the article
}

problems while improving the quality, validity and rigour of research and ensuring its continuity and sustainability [3]. Community research models may be particularly useful in diverse and deprived settings occupied by so-called "hard to reach" communities. Community researchers who are multilingual and have access to and knowledge of their own communities may improve recruitment and retention efforts [4].

However, community research models potentially involve complex power dynamics and discordant expectations [5], and it is in this light that we discuss the model for research practice and findings of our study in Sweden. The community research model was part of the UPWEB ${ }^{1}$

\footnotetext{
${ }^{1}$ https://www.birmingham.ac.uk/generic/upweb/index.aspx.
}

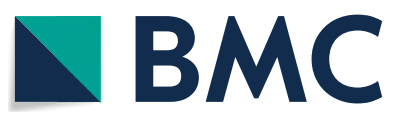

(c) The Author(s) 2018. This article is distributed under the terms of the Creative Commons Attribution 4.0 International License (http://creativecommons.org/licenses/by/4.0/), which permits unrestricted use, distribution, and reproduction in any medium, provided you give appropriate credit to the original author(s) and the source, provide a link to the Creative Commons license, and indicate if changes were made. The Creative Commons Public Domain Dedication waiver (http://creativecommons.org/ publicdomain/zero/1.0/) applies to the data made available in this article, unless otherwise stated. 
Table 1 Neighbourhood characteristics

\begin{tabular}{|c|c|c|c|}
\hline & Uppsala & Neighbourhood 1 (Gottsunda) & Neighbourhood 2 (Sävja) \\
\hline Location & $\begin{array}{l}67 \mathrm{~km} \text { north of } \\
\text { Stockholm }\end{array}$ & $7 \mathrm{~km}$ south west of city centre & $6 \mathrm{~km}$ south east of the city centre \\
\hline Population in 2016 & 214559 & 10198 & 6519 \\
\hline People with a foreign background & $52,649(24 \%)$ & $5568(54.5 \%)$ & $2188(29.7 \%)$ \\
\hline $\begin{array}{l}\text { Total average annual earnings }{ }^{\mathrm{a}} \text { in } 2015^{\mathrm{b}} \text {, thousand } \\
\text { Swedish crowns }\end{array}$ & 327.7 & 226 & 290 \\
\hline Unemployment rate in 2016 (16-64 years) & $5.5 \%$ & $8.6 \%$ & $5.3 \%$ \\
\hline Sick days ${ }^{c}$ in 2015 & 22.3 & 35.6 & 29.6 \\
\hline
\end{tabular}

a Average earnings is the sum of income from employment and business. Consists of the total current taxable income from employment, entrepreneurship, pension, sickness benefit and other taxable transfers. Does not include income from capital

b No statistics exist for 2016

c Sick days is the Swedish Social Insurance Agency's measure of the number of days of absence from work compensated by sickness benefit during a 12-month period

project exploring access to healthcare in diverse neighbourhoods. Community research is seldom used in Sweden: we have not found any published articles critically discussing its use here. This paper discusses challenges and lessons that can inform future applications of community research models, particularly in increasingly diverse research settings.

\section{Main text}

\section{Materials and methods}

The UPWEB project investigated access to healthcare in eight diverse neighbourhoods in four European countries (Sweden, Germany, Portugal, UK). The project aim was to understand how residents of superdiverse areas access healthcare, with specific aims to:

- Examine residents' experiences of accessing and communicating with healthcare providers and the approaches residents take to optimize their access to healthcare.

- Investigate the factors influencing people's access to, and experiences of, healthcare including local and national welfare states, health and migration regimes.

- Explore the ways in which different types of providers identify need and investigate the roles they adopt, and challenges and opportunities they face.

- Use the experiential knowledge of providers and residents to develop new models of provision and test the applicability of these models to a wider population.

The two Swedish neighbourhoods were in UppsalaSweden's fourth largest city-both highly diverse, comprising a mixture of long-term and recent residents of Swedish origins, and different migrant groups, both recent arrivals and those who had come to Sweden decades earlier. Diversified diversity was apparent, not only in terms of ethnicity, but also in terms of socioeconomic status, immigrant status, participation in the labour market, age, gender, and religion [6]. Both neighbourhoods in Uppsala were deprived with higher levels of poverty and annual sick leave days than the city average [7]. Table 1 below shows characteristics of these neighbourhoods in comparison to Uppsala municipality [8].

The project used mixed methods including ethnographic observations, in-depth qualitative interviews (with healthcare users and providers in the neighbourhoods who were not financially compensated) and a quantitative survey. Community researchers were recruited at the beginning of the project to carry out both ethnographic observations and in-depth interviews alongside the academic research team.

The project's community research model was developed in the UK by Goodson and Phillimore [2] and adopted in the other three countries. The aim was to recruit local community members from key minorities, train them in qualitative research methods, and support them in engaging their own communities in research. Community researchers could introduce the research project to their networks, map the locality, recruit interviewees, translate interviews and, in some cases, conduct and transcribe interviews. The model had originally been developed for researching "hard to reach" communities, such as refugees, in the UK.

\section{Recruitment and training of community researchers in Sweden}

The position of community researcher was advertised locally in Uppsala. Established contacts from the study neighbourhoods were encouraged to apply. The vacancy was also advertised in the neighbourhoods' cultural centres and Uppsala University's Department of Public Health. 
Table 2 Characteristics of community researchers

\begin{tabular}{|c|c|c|c|c|c|}
\hline $\begin{array}{l}\text { Community } \\
\text { researcher }\end{array}$ & Age group & Educational level & $\begin{array}{l}\text { Residency at the time } \\
\text { of the study }\end{array}$ & Languages spoken & $\begin{array}{l}\text { Other employment } \\
\text { at the time of the study }\end{array}$ \\
\hline 1 & $20-30$ & $\begin{array}{l}\text { Master degree in public } \\
\text { health }\end{array}$ & $\begin{array}{l}\text { Uppsala outside of the } \\
\text { neighbourhoods }\end{array}$ & Swedish, English, Finnish & None \\
\hline 2 & $20-30$ & Bachelor degree & $\begin{array}{l}\text { Uppsala outside of the } \\
\text { neighbourhoods }\end{array}$ & Swedish, English, Somali & None \\
\hline 3 & $20-30$ & Secondary school & Neighbourhood 2 & Swedish, Arabic & Employed at a leisure centre \\
\hline 4 & $20-30$ & $\begin{array}{l}\text { Master degree in public } \\
\text { health }\end{array}$ & Neighbourhood 1 & Swedish, English, Arabic & None \\
\hline 5 & $40-50$ & Bachelor degree & Neighbourhood 1 & $\begin{array}{l}\text { Swedish, English, Swahili, } \\
\text { Somali }\end{array}$ & $\begin{array}{l}\text { Manager at a citizen educa- } \\
\text { tion organisation }\end{array}$ \\
\hline
\end{tabular}

Five community researchers were recruited speaking various languages other than Swedish, including English, Finnish, Somali, Swahili and Arabic. Community researchers were hired on a short-term temporary hourly basis. Two days of training in qualitative research methods, including interviewing, ethics and transcription, and an introduction to the project were conducted by the main project researchers in Sweden. Two of the community researchers did not reside in the study neighbourhoods but had language and research skills that were useful to the project. See Table 2 for further details of the community researchers.

Overall, the community researchers assisted in recruiting and interviewing 35 healthcare users and 15 healthcare providers and Table 3 shows some of their characteristics.

Public health and health promotion in Sweden is integral to society and community researchers assisted in recruiting and interviewing 10 women and 5 men healthcare providers from education, youth work, sport and library services as well as primary care, midwifery, pharmacy, elder care and psychiatry. Due to confidentiality issues, further individual identifying information for the healthcare providers is withheld.

\section{Community research in action}

Community researchers recruited study participants from the neighbourhoods, independently conducted or assisted during interviews and carried out ethnographic observations. Their individual involvement and interest in the project varied considerably. For various reasons it was difficult to recruit and retain community researchers in Sweden. The project mainly attracted applications from unemployed graduates. Only one community researcher who already had an interest in research (and a master's degree in international health) worked with the project until all interviews were conducted and transcribed.
The community researchers' local networks and knowledge about the neighbourhoods were invaluable for contextualizing the study and identifying and recruiting participants. While community researchers facilitated access to some groups, they were less able to reach and recruit others groups (such as intra-European migrants including Roma) due to language barriers and the limits of their networks. The limited number of community researchers appointed from the start was partly due to the high cost and bureaucratic burden of hiring community researchers in the Swedish context. Moreover, benefits to the individuals who were undertaking community research were not apparent. The community research model assumed certain ideal conditions for its implementation, which were not present and which, together with various contextual factors, contributed to problems in adopting the model in Sweden and are discussed below.

\section{Ideal conditions What community means}

This project sampled by neighbourhood, which in Sweden implies clearly delimited urban areas built around specific facilities such as schools, library, healthcare centre, etc. The research project assumed that people living in such a neighbourhood considered it not just a place of residence, but also identified with the locality with some sense of community.

Defining the community as both a locality and an identity, assumed that people living in the neighbourhood had some sense of community in relation to the geographical location. In both Swedish neighbourhoods, community researchers did describe a shared community identity but they had different perspectives on how this manifested itself. For some it was a positive sense of belonging whereas for others it was more negatively expressed as a feeling of "us against the world". Both neighbourhoods are very diverse, and to some extent socioeconomically segregated and racialised [9] with residents of certain areas within the neighbourhood wanting to distinguish 
Table 3 Healthcare users' characteristics

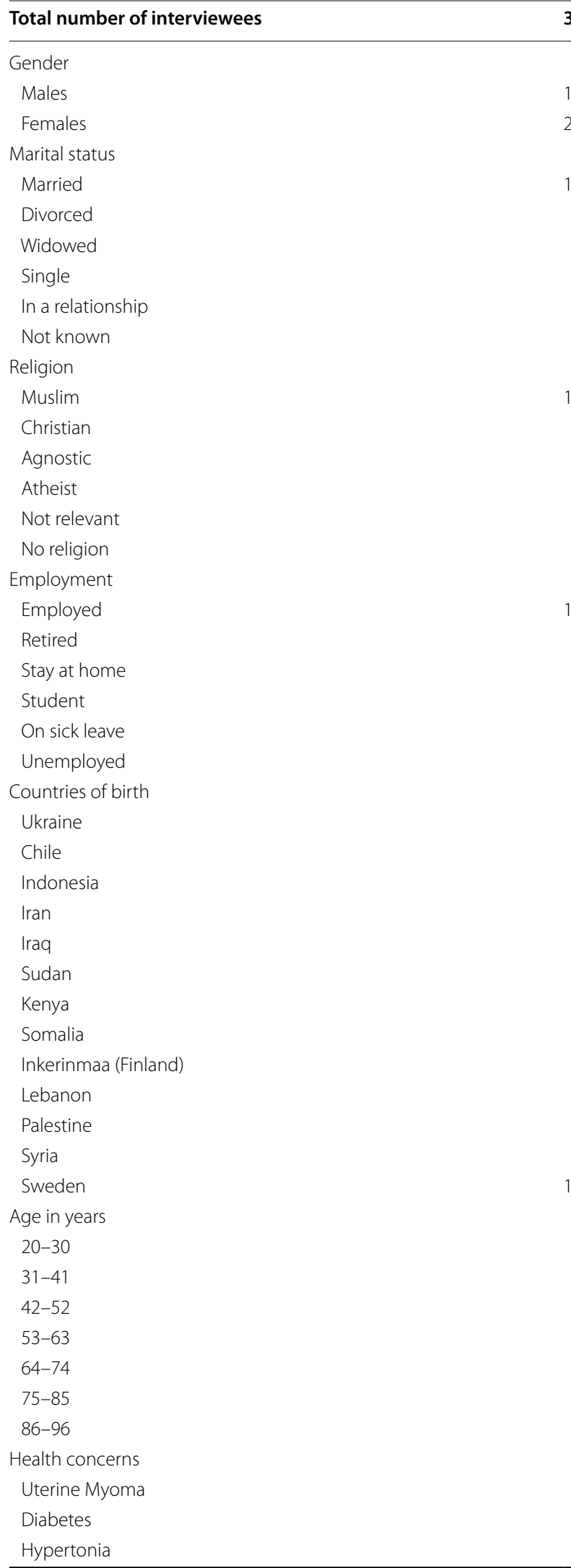

Table 3 (continued)

Total number of interviewees

35

Heart failure 2

Other heart problems 3

Mental illness $\quad 7$

Missing tooth 1

Hand injury 1

Arthritis 1

Epilepsy

Hypothyroidism

Fibromyalgia

Chronic obstructive pulmonary disease

Haemorrhoids

Rheumatism

Lung embolism

Asthma

Dental caries

Impaired kidney function

Chronic pain

Allergies

Eye condition

Irritable bowel syndrome

Multiple sclerosis

Languages spoken

Swedish

Finnish

English

Greek

Italian

Indonesian

Hindi

Chinese

Arabic

Kurdish

German

Persian

Swahili

Tigrigna

Amharic

Somali

Kikuyu

Russian

Ukrainian

Spanish

German

French

Norwegian

Dutch

Italian

2
3
7
1
1
1
1


themselves from the rest of the neighbourhood. A community is not homogenous and researchers identified differently with the community, as residents and nonresidents, offering different versions of an "insider" perspective.

\section{Community ownership}

The community research model [2] assumes that there is both interest in and capacity for participation among community members who can contribute to, and get something out of participating in research [10]. However, in the Swedish case community researchers were not fully part of the research process, for instance not having contributed to the research design and the choice of methods. While empowerment and co-ownership are central aspects of the community research model, we found the possibilities for this were limited. Two active community researchers, who were curious about how research could feed into policy and practice, got involved in the project, but the community research model was only partly successful in embedding the project as a collaboration between community members and the University. The research remained University-led with a top-down approach contributing to a limited sense of community ownership.

\section{Contextual factors Refugee arrivals}

The study took place during 2015-2016 when 163,000 asylum-seekers arrived in Sweden [11]. The need to find housing, access education and other services for these new arrivals, many of whom spoke neither English nor Swedish, put considerable strain on local authorities, community organisations, and cooperative associations (föreningar) in the study neighbourhoods. In particular, the arrival of unaccompanied refugee minors during the summer of 2015 [12] kept key contacts in both neighbourhoods fully occupied. These key contacts were the very people with valuable "insider knowledge" who might have otherwise have been employed as community researchers.

\section{Employment conditions}

Employing several people on short-term contracts is complicated as Swedish Universities are public authorities or state agencies (myndighet) with all the bureaucracy that comes with being a state institution [13]. Temporary, part-time work without a contract can be offered on an hourly paid basis ${ }^{2}$ to students and others where the work

\footnotetext{
${ }^{2}$ Hourly rates in 2016 were paid at approximately 13 Euros per hour, plus $12 \%$ vacation pay.
}

is assumed not to be their main source of income. There is a strong expectation of stable full-time employment in the Swedish labour market and flexible part-time work is seen as undesirable. Short-term contracts are complicated and expensive to administer, as all state employees are entitled to benefits such as paid leave, and after a period of time temporary contracts are expected to be made permanent [14]. Since the cost of living and the level of personal income tax are high [15], it is difficult to survive with short-term temporary hourly work, as was available for community researchers. As was already mentioned, project-based employment was possible but beyond the bureaucratic challenges, it was not attractive to potential community researchers, who tended to prefer more reliable forms of employment with more remunerative and secure longer-term prospects, even if they had an interest in the research.

\section{Conclusion}

Community research is beneficial in accessing participants and promoting co-ownership of research, especially in deprived areas that might otherwise be excluded from research. Ideally community research should begin with a topic that originates from the community itself [5] which was not the case in this project. The community researchers were not involved in the proposal writing and interview preparation, which limited the possibility of developing co-ownership, and may have contributed to a lack of enthusiasm. Thus, community researchers' interests were not embedded in the research from its outset and no real shift in the traditional power dynamics of research occurred. This raises the question of how community research can work within an institutional setting [16], especially in a country such as Sweden where universities are bureaucratic public agencies.

Community participation in research is not necessarily a need or demand arising from within a community but may rather reflect academic discourse on the ethics of knowledge production and innovative research methods. Having a sense of shared interests with one's neighbourhood cannot be assumed, and even where a sense of community exists, equitable participation in research is difficult due to power imbalances within a community.

\section{Limitations}

The community research model can be interrogated in terms of assumptions about community and context-specific factors of implementation. In terms of identifying and recruiting research participants, relying on community researchers' networks may lead to convenience sampling rather than an agreed sampling strategy. Poor research validity and reliability, have been highlighted as challenges of community research models [5]. While 
training community researchers and paired interviewing supports validity and reliability, more extensive training and regularly debriefing, especially for those new to research are recommended. Models of community research are specific to culture and place and cannot be simply exported to another context. A context analysis may support applicability and sustainability of community research.

\section{Abbreviations}

UPWEB: understanding the practice and developing the concept of welfare bricolage; UK: United Kingdom.

\section{Authors' contributions}

HB was responsible for the UPWEB project in Sweden. AJM worked as a researcher in the project. SH worked as a research assistant. SK worked as a community researcher. $\mathrm{HB}$ and $\mathrm{AJM}$ provided training to the community researchers. HB conceptualised the article. SH first drafted the article, in discussion with SK. Interpretations were contributed by all authors. All authors read and approved the final manuscript.

\section{Author details}

${ }^{1}$ Department of Sociology, Uppsala University, Uppsala, Sweden. ${ }^{2}$ MRC Epidemiology Unit, University of Cambridge, Cambridge, UK. ${ }^{3}$ SIDRA Institute, Garowe, Somalia.

\section{Acknowledgements}

The UPWEB team acknowledges the contribution of community researchers and research participants.

\section{Competing interests}

The authors declare that they have no competing interests.

\section{Availability of data and materials}

The coded data-set is not made available, due to concerns about people in small neighbourhoods being identifiable. Coded transcripts, appropriately de-identified, can be obtained on request.

\section{Consent for publication}

Not applicable.

\section{Ethical approval and consent to participate}

Ethical approval for the UPWEB project in Sweden was obtained from the Swedish ethical committee (etiknämnden) in Uppsala in 2015, (diarienummer 2015/112). Both written and verbal consent was obtained from all participants in the study.

\section{Funding}

Understanding the practice and developing the concept of welfare bricolage-UPWEB funded by the Norface Welfare State Futures programme, Number 462-14-090.

\section{Publisher's Note}

Springer Nature remains neutral with regard to jurisdictional claims in published maps and institutional affiliations.
Received: 19 April 2018 Accepted: 20 August 2018

Published online: 25 August 2018

\section{References}

1. Klingberg S, Bradby H, Hamed S. 006 OP: Researching health and welfare in superdiverse neighbourhoods: reflections on using a community research model in Uppsala. Sweden, BMJ Open. 2017;7(Suppl 2):A2-3.

2. Community Research for Participation. http://www.press.uchicago.edu/ ucp/books/book/distributed/C/bo13321606.html. Accessed 2 Feb 2018.

3. Israel BA, Parker EA, Rowe Z, Salvatore A, Minkler M, López J, et al. Community-based participatory research: lessons learned from the centers for children's environmental health and disease prevention research. Environ Health Perspect. 2005;113(10):1463-71.

4. Ahmadi D. Serving diverse communities: the role of community initiatives in delivering services to poverty neighbourhoods. Cities. 2017;69(Supplement C):86-94.

5. Minkler M. Community-based research partnerships: challenges and opportunities. J Urban Health Bull NY Acad Med. 2005;82(Suppl 2):ii3-12.

6. Phillimore J, Bradby H, Knecht M, Padilla B, Brand T, Cheung SY, et al. Understanding healthcare practices in superdiverse neighbourhoods and developing the concept of welfare bricolage: protocol of a cross-national mixed-methods study. BMC Int Health Hum Rights. 2015;28(15):16.

7. Bradby H, Hamed S. typologies and logics of welfare bricolage in Sweden: Uppsala case study; 2017. https://www.birmingham.ac.uk/Documents/ college-social-sciences/social-policy/iris/2017/IRiS-WP-21-2017UPWEB7 pdf. Accessed 2 Feb 2018

8. Uppsala Kommun. Områdesfakta 2016 Statistik för kommunens geografiska områden; 2016. https://www.uppsala.se/contentassets/f09f9 e6b994f41408c66064a2da8470b/omradesfakta-2016.pdf. Accessed 1 June 2018.

9. Molina I. Stadens rasifiering : Etnisk boendesegregation i folkhemmet : [ethnic residential segregation in the Swedish Folkhem]; 1997. http:// uu.diva-portal.org/smash/record.jsf?pid=diva2\%3A161611\&dswid $=-5753$. Accessed 28 Oct 2016.

10. Wallerstein Nina B, Duran Bonnie. Using community-based participatory research to address health disparities. Health Promot Pract. 2006;7(3):312-23.

11. Migrationsverket. Nästan 163000 människor sökte asyl i Sverige 2015 Migrationsverket; 2017. http://www.migrationsverket.se/Om-Migrations verket/Nyhetsarkiv/Nyhetsarkiv-2016/2016-01-01-Nastan-163-000-manni skor-sokte-asyl-i-Sverige-2015.html. Accessed 25 Jan 2017.

12. Migrationsverket. Statistics_Swedish Migration Agency; 2016. http:// www.migrationsverket.se/English/About-the-Migration-Agency/Facts -and-statistics-/Statistics.html. Accessed 28 Oct 2016.

13. Universities and University Colleges. UKÄ (Swedish Higher Education Authority). http://english.uka.se/facts-about-higher-education/highe r-education-institutions-heis/universities-and-university-colleges.html. Accessed 28 Mar 2018.

14. Nunziata L, Staffolani S. Short-term contracts regulations and dynamic labour demand: theory and evidence. Scott J Polit Econ. 2007;54(1):72-104

15. OECD. Taxing Wages 2016. OECD Publishing; 2016. (Taxing Wages). http:// www.oecd-ilibrary.org/taxation/taxing-wages-2016_tax_wages-2016-en. Accessed 2 Feb 2018.

16. Polanyi MC. Opportunities and Pitfalls of Community-Based Research: A Case Study. Mich J Community Serv Learn. 2003 Summer;9(3). http://hdl. handle.net/2027/spo.3239521.0009.302. Accessed 1 June 2018. 